\title{
Interaction of MDIMP with the Voltage-Gated Calcium Channels ${ }^{\text {ฐ }}$
}

\author{
Juan A.M. De La Rosa, Maricela García-Castañeda, Takuya Nishigaki, Juan Carlos Gómora, \\ Teresa Mancilla-Percino, and (1) Guillermo Ávila
}

Departamento de Bioquímica (J.A.M.D.L.R., M.G.-C., G.Á.) and Departamento de Química (T.M.-P.), Cinvestav-IPN, Mexico City, Mexico and Instituto de Biotecnología (T.N.) and Instituto de Fisiología Celular (J.C.G.), Universidad Nacional Autónoma de México, Cuernavaca, Mexico

Received March 10, 2020; accepted June 11, 2020

\begin{abstract}
Amino acid-derived isoindolines are synthetic compounds that were created with the idea of investigating their biological actions. The amino acid moiety was included on the grounds that it may help to avoid toxic effects. Recently, the isoindoline MDIMP was shown to inhibit both cardiac excitation-contraction coupling and voltage-dependent calcium channels. Here, we revealed that MDIMP binds preferentially to low-voltage-activated (LVA) channels. Using a holding potential of $-90 \mathrm{mV}$, the following $I_{50}$ values were found (in micromolars): $>1000$ (Cav2.3), 957 (Cav1.3), 656 (Cav1.2), 219 (Cav3.2), and 132 (Cav3.1). Moreover, the isoindoline also promoted both accelerated inactivation kinetics of high-voltage-activated $\mathrm{Ca}^{2+}$ channels and a modest upregulation of $\mathrm{Cav}_{\mathrm{v}} 1.3$ and $\mathrm{Ca}_{\mathrm{v}} 2.3$. Additional data indicate that although MDIMP binds to the closed state of the channels, it has more preference for the inactivated one. Concerning Cav3.1, the compound did not alter the shape of the instantaneous currentvoltage curve, and substituting one or two residues in the selectivity filter drastically increased the $\mathrm{IC}_{50}$ value, suggesting that MDIMP binds to the extracellular side of the pore. However,
\end{abstract}

an outward current failed in removing the inhibition, which implies an alternative mechanism may be involved. The enantiomer (R)-MDIMP [methyl (R)-2-(1,3-dihydroisoindol-2-yl)-4methylpentanoate], on the other hand, was synthesized and evaluated, but it did not improve the affinity to LVA channels. Implications of these findings are discussed in terms of the possible underlying mechanisms and pharmacological relevance.

\section{SIGNIFICANCE STATEMENT}

We have studied the regulation of voltage-gated calcium channels by MDIMP, which disrupts excitation-contraction coupling in cardiac myocytes. The latter effect is more potent in atrial than ventricular myocytes, and this could be explained by our results showing that MDIMP preferentially blocks lowvoltage-activated channels. Our data also provide mechanistic insights about the blockade and suggest that MDIMP is a promising member of the family of $\mathrm{Ca}^{2+}$ channel blockers, with possible application to the inhibition of subthreshold membrane depolarizations.

\section{Introduction}

Voltage-gated ion channels are proteins found in most cells of an organism and are responsible for regulating rapid ion transport across the plasma membrane (Terlau and Stühmer, 1998). In particular, voltage-gated $\mathrm{Ca}^{2+}$ channels (VGCCs) allow the entry of this second messenger and thereby influence several cellular processes. The VGCCs can be classified as lowand high-voltage-activated (LVA and HVA), as well as of type L, N, P/Q, R, and T. Interestingly, LVA and HVA channels differ in the residues providing electronegativity to the four homologous domains of their selectivity filter. The former contains two glutamates and two aspartates (EEDD), whereas

Part of this work was presented at the Biophysical Society Annual Meeting. March 02-06, 2019; Baltimore, MD.

This work was supported by Consejo Nacional de Ciencia y Tecnologia [Grant 253009] to G.A.

https://doi.org/10.1124/mol.120.119982.

S This article has supplemental material available at molpharm. aspetjournals.org. the latter has four glutamates (EEEE; Catterall, 2011). The L-type channels are sensitive to low concentrations $(<10 \mu \mathrm{M})$ of dihydropyridines (DHPs; Hess et al., 1984), and each cell type possesses its kit of channels. The case of VGCCs of atrial and ventricular myocytes is typical. In adult rats, for example, the former expresses both HVA $\left(\mathrm{Ca}_{\mathrm{V}} 1.2, \mathrm{Ca}_{\mathrm{v}} 1.3\right.$, and $\left.\mathrm{Ca}_{\mathrm{V}} 2.3\right)$ and LVA (Cav3.1 and Cav3.2) channels, whereas the latter primordially expresses $\mathrm{Ca}_{\mathrm{v}} 1.2$ (Piedras-Rentería et al., 1997; Larsen et al., 2002; Perez-Reyes, 2003; Zhang et al., 2005; Zamponi et al., 2015; Ríos-Pérez et al., 2016).

The isoindolines are heterocyclic compounds consisting of a six-membered benzene ring fused to a five-membered ring containing a nitrogen atom at position two (Speck and Magauer, 2013). Molecular docking studies suggest that some of these compounds (isoindolines 2-substituted derivatives from $\alpha$-amino acids) could bind to an L-type $\mathrm{Ca}^{2+}$ channel (Cav1.2). In particular, both the isoindoline MDIMP (also known as 1b) and a DHP antagonist showed similar binding profiles for $\mathrm{Ca}_{\mathrm{V}}$ 1.2. Moreover, the in silico model also predicts

ABBREVIATIONS: $\mathrm{Ca}_{\mathrm{v}}$, voltage-gated calcium channel; COX, cyclooxygenase; DHP, dihydropyridine; EC, excitation-contraction; $\mathrm{G}_{\mathrm{max}}, \mathrm{maximal}$

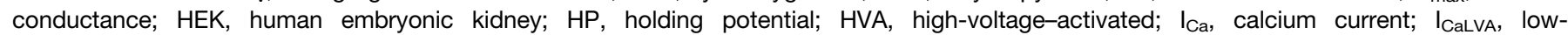
voltage-activated $\mathrm{Ca}^{2+}$ current; I-V curve, current-voltage curve; k, slope factor; LVA, low-voltage-activated; MDIMP, methyl (S)-2-(1,3dihydroisoindol-2-yl)-4-methylpentanoate; (R)-MDIMP, methyl (R)-2-(1,3-dihydroisoindol-2-yl)-4-methylpentanoate; VGCC, voltage-gated calcium channel; $V_{m}$, membrane potential. 
that MDIMP binds to segments S5, S6, and loop P (of domain II) by interacting with residue $\mathrm{F} 763$ (S6) and the glutamate of the selectivity filter (E736; Mancilla-Percino et al., 2010).

A previous work challenged the possibility that MDIMP regulates VGCCs in cardiac myocytes. Remarkably, the compound reduced the magnitude of both LVA and HVA calcium currents, acting more potently on the former. Additionally, MDIMP inhibited excitation-contraction (EC) coupling in both atrial and ventricular myocytes (Santamaria-Herrera et al., 2016). This demonstrates that the isoindolines effectively target VGCCs and thereby also impair EC coupling.

Here, we have investigated whether MDIMP selectively blocks a specific type of $\mathrm{Ca}^{2+}$ channel by using heterologous expression systems. Indeed, our results show that MDIMP acts preferentially on $\mathrm{Ca}_{\mathrm{V}} 3.1$ and $\mathrm{Ca}_{\mathrm{V}} 3.2$ (LVA channels). Additional findings suggest that the occupancy of the binding site is state-dependent: the inactivated state enhances the affinity, and the site is also partially available in the closed configuration. We also describe experimental conditions that allow MDIMP to partially discriminate between two L-type calcium channels, $\mathrm{Ca}_{\mathrm{v}} 1.2$ and $\mathrm{Ca}_{\mathrm{v}} 1.3$. The effect on $\mathrm{Ca}_{\mathrm{v}} 3.1$ channels was further characterized, and results from two mutations in the selectivity filter of this channel (DEDD and DDDD) suggest that this region might be important for the interaction (the potency of the blockade is reduced by 3 - and 5 -fold). Interestingly, however, we observed a similar percentage of inhibition on inward and outward currents, indicating that imposing a driving force for the efflux of ions does not unplug the ion conducting pathway. Finally, MDIMP did not alter the shape of the instantaneous I-V curve, suggesting that the effect on a particular channel is all-or-none.

A preliminary report was presented recently (De La Rosa et al., 2019).

\section{Materials and Methods}

Cell Culture and Transfection. Human embryonic kidney (HEK) 293T/17 cells, a subclone of the HEK293 cell line, were acquired from the American Type Cell Culture Collection (ATCC CRL-11268) and were grown and transfected as described previously (Santamaria-Herrera et al., 2016). The following cDNAs (GenBank accession number included) were used: Cav1.2 (AY728090), Cav1.3 (AF370009), Cav2.3 (X67856), $\beta_{2 \mathrm{a}}$ (M80545), and $\alpha_{2} \delta-1$ (M21948). The transfection mix consisted of equimolar amounts of cDNA encoding for one principal channel subunit, both accessory subunits, and Enhanced Green Fluorescent Protein, as a reporter gene. In another set of experiments, 293T/17 cells were transfected with cDNAs encoding Enhanced Green Fluorescent Protein and mutant proteins of $\mathrm{Ca}_{\mathrm{V}} 3.1$ (either DEDD or DDDD; GarzaLópez et al., 2016). FuGENE HD (Promega, Madison, WI) was used as a transfection reagent according to the provider's instructions. All recordings were performed 48-72 hours post-transfection in green fluorescent cells. The activity of wild-type LVA channels (Cav3.1AF190860 and Cav3.2-AF051946) was also investigated in HEK293 cells stably transfected with the corresponding cDNAs (Díaz et al., 2005; Lopez-Charcas et al., 2012).

Voltage-Clamp Experiments. Calcium currents $\left(\mathrm{I}_{\mathrm{Ca}}\right)$ were recorded using the whole-cell patch-clamp technique, as described elsewhere (Santamaria-Herrera et al., 2016). Unless otherwise specified, the holding potential (HP) was $-90 \mathrm{mV}$. The whole-cell series resistance and cell capacitance were estimated using the capacitance cancellation feature of the amplifier (Axopatch 200B; Molecular Devices, LLC, San Jose, CA), and other linear components of the current signal were digitally eliminated (with a leak subtraction protocol, termed "P/N"). Series resistance was electronically compensated (by 60\%-70\%), and its final values were typically 1 to $2 \mathrm{M} \Omega$. $\mathrm{I}_{\mathrm{Ca}}$ was analogically filtered (at either 2 or $10 \mathrm{kHz}$ ) using the four-pole low-pass Bessel filter of the amplifier, digitalized by an analogical-to-digital converter (Digidata 1322; Molecular Devices, LLC), and stored for off-line analysis. $\mathrm{I}_{\mathrm{Ca}}$ was assessed before, during, and after bathing the cells with MDIMP, its enantiomer ((R)-MDIMP ), or the vehicle (dimethyl sulfoxide [DMSO]).

In general, $\mathrm{I}_{\mathrm{Ca}}$ was elicited by voltage steps delivered every 15 seconds, from the HP to either $-20 \mathrm{mV}$ (LVA channels) or $+20 \mathrm{mV}$ (HVA channels). For each particular cell, $\mathrm{I}_{\mathrm{Ca}}$ values were normalized to those observed at $\sim 105$ seconds after break-in into the whole-cell mode, and at that time, MDIMP was applied, typically in two consecutive concentrations, followed by washout. In some cells, the behavior of $\mathrm{I}_{\mathrm{Ca}}$ was assessed in the presence of only the control external solution (here termed "basal" $\mathrm{I}_{\mathrm{Ca}}$ ). To estimate the percentage of MDIMP effect, the $I_{C a}$ values observed in the presence of the compound were normalized to those of time-matched basal. Unless specified otherwise, the concentration-response curves were built from peak values of current traces and fitted according to the following Hill equation:

$$
\left.\mathrm{I}_{\mathrm{Ca}}=100 /\left(1+[\mathrm{MDIMP}] / \mathrm{IC}_{50}\right) \exp \left(\mathrm{n}_{\mathrm{H}}\right)\right)
$$

where $\mathrm{I}_{\mathrm{Ca}}$ represents the percentage of inhibition, [MDIMP] is the MDIMP concentration, $\mathrm{IC}_{50}$ is the [MDIMP] required to $50 \%$ of the effect, and $\mathrm{n}_{\mathrm{H}}$ is the Hill coefficient.

To investigate the steady-state voltage dependence of inactivation, 5 -second conditioning pulses to different potentials preceded a test pulse to -20 or $+20 \mathrm{mV}$ (LVA and HVA channels, respectively). Subsequently, the relative values of $\mathrm{I}_{\mathrm{Ca}}$ were plotted as a function of membrane potential during prepulses, and the resulting inactivation curves were fitted according to the following Boltzmann equation:

$$
\mathrm{I}_{\mathrm{Ca}}=\mathrm{I}_{\max } /\left(1+\exp \left[\left(\mathrm{V}_{\mathrm{m}}-\mathrm{V}_{1 / 2}\right) / \mathrm{k}\right]\right)
$$

where $I_{\max }$ represents the maximum current recruited at very negative potentials, $\mathrm{V}_{1 / 2}$ is the potential required to reach $50 \%$ of inactivation, and $\mathrm{k}$ is the slope factor.

Finally, the voltage dependence of activation was assessed by fitting current-voltage curves (I-V curves) to the following Boltzmann equation:

$$
\left.\mathrm{I}_{\mathrm{Ca}}=\mathrm{G}_{\mathrm{max}}\left(\mathrm{V}_{\mathrm{m}}-\mathrm{V}_{\text {rev }}\right) /\left(1+\exp \left[-\left(\mathrm{V}_{\mathrm{m}}-\mathrm{V}_{1 / 2}\right)\right) / \mathrm{k}\right]\right)
$$

where $G_{\max }$ is the maximal conductance, $V_{m}$ is the membrane potential, $\mathrm{V}_{\text {rev }}$ represents the apparent reversal potential, $\mathrm{V}_{1 / 2}$ is the membrane potential required to activate $50 \%$ of $\mathrm{G}_{\max }$, and $\mathrm{k}$ is the slope factor.

Recording Solutions. Unless otherwise specified, cells were bathed in an external solution containing (in millimolars) $10 \mathrm{CaCl}_{2}$, 150 tetraethylammonium chloride, 10 HEPES, and 10 glucose $(\mathrm{pH}$ 7.3). Besides, the internal (pipette) solution contained (in millimolars) 140 Cs-Asp, 10 Cs-EGTA, $10 \mathrm{CsCl}, 2 \mathrm{CaCl}_{2}, 5 \mathrm{Mg}$-ATP, 0.05 Tris-GTP, 5 glucose, and 10 HEPES ( $\mathrm{pH} 7.3$ ).

Stock solutions (100 mM) of MDIMP and its enantiomer $((R)$ MDIMP ) were prepared using DMSO as the solvent and then were diluted in the external recording solution for obtaining final working concentrations. When high molarities of the compounds (i.e., 0.5-1 $\mathrm{mM}$ ) were used, the external solution was warmed to avoid precipitation ( 10 minutes, $\sim 50^{\circ} \mathrm{C}$; in a water bath). Indeed, concentrations higher than $1 \mathrm{mM}$ were not investigated because MDIMP tends to precipitate beyond this concentration. New working solutions were prepared daily, and direct exposure to light was avoided (although we do not know whether MDIMP is lightsensitive). The exchange of external solutions was performed by a fast perfusion system (SF-77B; Warner Instruments, LLC, Hamden, CT) that was digitally controlled. For all channel types, the vehicle alone (DMSO) was tested at concentrations in which its mixture with MDIMP elicited a drastic reduction on $\mathrm{I}_{\mathrm{Ca}}$, and the solvent per se failed in producing significant changes. 
Synthesis of (R)-MDIMP . The strategy for synthesizing the new enantiomer $(R)$-MDIMP is illustrated as auxiliary material (Supplemental Fig. 1). Briefly, 1) the D-leucine methyl ester hydrochloride was prepared from D-leucine and trimethylsilyl chloride in methanol according to the method described elsewhere (Li and Sha, 2008). 2) Then, the new ( $R$ )-MDIMP was obtained from the reaction of D-leucine methyl ester hydrochloride, $\alpha, \alpha$-dibromoo-xylene, and $\mathrm{KHCO}_{3}$ in acetonitrile following the same strategy as for MDIMP (Mancilla-Percino et al., 2001). The structure of ( $R$ )-MDIMP was characterized by ${ }^{1} \mathrm{H}$ and ${ }^{13} \mathrm{C}$ NMR and high-resolution mass spectrum (see Supplemental Fig. 1 for further details).

Statistical Analysis. All data are presented as means \pm S.D. and were analyzed and plotted with the combined use of software suites: p-CLAMP (version 10.2; Molecular Devices) and SigmaPlot (version 12.3; Systat Software Inc; San Jose, CA). Statistical significance was evaluated using two-tailed paired Student's $t$ tests. All experiments were performed at room temperature $\left(22-24^{\circ} \mathrm{C}\right)$.

\section{Results}

Our main aim was to investigate the effects of MDIMP on cardiac VGCCs expressed in heterologous systems. This experimental approach guarantees the identity of each particular channel and thus contributes to a better understanding of the underlying mechanisms. We began using an HP of $-90 \mathrm{mV}$, which keeps most of the channels in the closed state.

In addition, we initially focused on the L-type $\mathrm{Ca}^{2+}$ channels $\mathrm{Ca}_{\mathrm{V}} 1.3$ (Fig. 1, A-D) and Cav1.2 (Fig. 1, E and F). For each channel type, the basal levels of $\mathrm{I}_{\mathrm{Ca}}$ were estimated under control conditions; that is, the behavior of $\mathrm{I}_{\mathrm{Ca}}$ was studied as a function of time and in the absence of MDIMP. Figure 1A (open circles) provides an example of such basal behavior. It can be seen that the basal $\mathrm{I}_{\mathrm{Ca}}$ of $\mathrm{Ca}_{\mathrm{V}} 1.3$ decreases steadily within the next 10 minutes after having initiated the recordings (to an $\sim 85 \%$ of its initial magnitude). Another pool of cells was consecutively exposed to 750 and $1000 \mu \mathrm{M}$ of MDIMP, and this led to a higher decrease in the magnitude of $\mathrm{I}_{\mathrm{Ca}}$ compared with the basal behaviour (Fig. 1A, green triangles). MDIMP was then washed out, and the $\mathrm{I}_{\mathrm{Ca}}$ slightly recovered from inhibition (Fig. 1A, open triangles). Results obtained from cells exposed to the compound were then divided by their timematched basal to only focus on MDIMP effects (which applies to all subsequent data). This analysis revealed that 750 and $1000 \mu \mathrm{M}$ of MDIMP reduce the magnitude of $\mathrm{I}_{\mathrm{Ca}}$ by $\sim 20 \%$ and $\sim 40 \%$, respectively (Fig. 1B).

With additional data, a concentration-response curve was built (Fig. 1C), and the following values of $\mathrm{IC}_{50}$ and Hill coefficient were obtained: $957 \mu \mathrm{M}$ and 3.5 (these parameters are also shown in Supplemental Table 1, together with those obtained for all channel types and experimental conditions). Of note, a low MDIMP concentration $(250 \mu \mathrm{M})$ promoted a slight increase in the activity of the Cav1.3 channel (see representative traces of Fig. 1D). As a result of this effect, the concentration-response curve showed a small but significant deviation toward negative values (of $\sim 20 \%$, Fig. 1C). Thus, in the presence of MDIMP, the $\mathrm{I}_{\mathrm{Ca}}$ of $\mathrm{Ca}_{\mathrm{V}} 1.3$ likely reflects a balance between degrees of stimulation and inhibition.

Figure 1 also shows a summary of MDIMP effects on $\mathrm{Ca}_{\mathrm{v}} 1.2$ (Fig. 1, E and F). The corresponding $\mathrm{IC}_{50}$ was $656 \mu \mathrm{M}$, which is higher than a value previously reported ( $452 \mu \mathrm{M}$; SantamariaHerrera et al., 2016). This apparent inconsistency is likely due
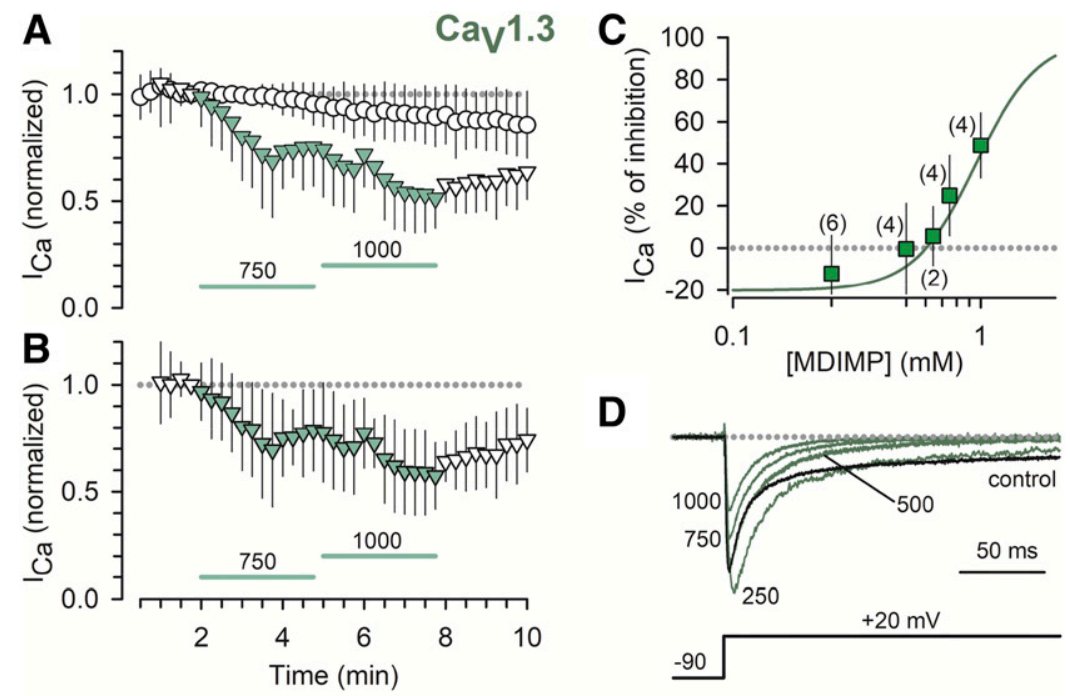

D

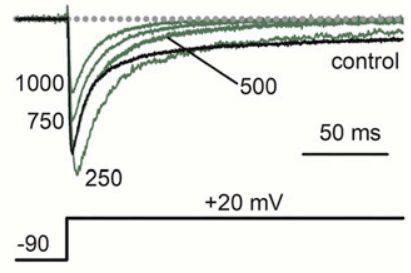

E

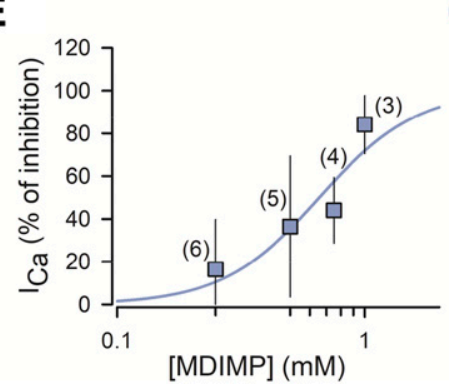

Cav1.2

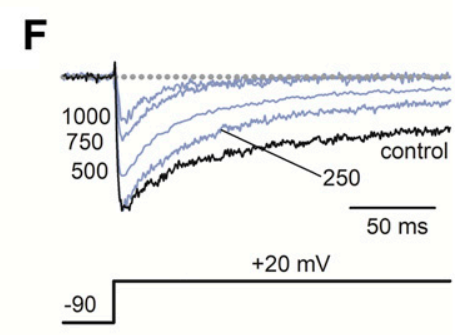

Fig. 1. MDIMP effects on L-type $\mathrm{Ca}^{2+}$ channels. (A) The open circles represent $\mathrm{I}_{\mathrm{Ca}}$ of $\mathrm{Ca}_{\mathrm{V}} 1.3$ that was recorded as a function of time under control or basal conditions $(n=6)$. Another cell group (triangles, $n=3$ ) was consecutively exposed to 750 and $1000 \mu \mathrm{M}$ of MDIMP (green symbols), and then the compound was washed out (open triangles). All results obtained from each particular cell were normalized by the absolute $\mathrm{I}_{\mathrm{Ca}}$ value that was observed at minute 1.75 (just before MDIMP application). (B) Same data set shown as triangles in (A) but divided by the corresponding timematched basal [(A) circles]. (C) Concentration-response curve built from data obtained as in (B). MDIMP $(250 \mu \mathrm{M})$ increased the peak magnitude of $\mathrm{I}_{\mathrm{Ca}}$ (data point with negative values), and thus the curve was fitted according to a slightly modified version of eq. 1 . Specifically, a constant was added to account for the negative deviation $(-20.2 \%)$. (D) Representative current traces obtained from $\mathrm{Ca}_{\mathrm{V}} 1.3$ expressing cells in the presence of distinct MDIMP concentrations (numbers, in micromolars). The currents were normalized to the peak value of the control (black trace). (E and F) Concentration-response curve (E) and representative traces $(\mathrm{F})$ obtained from $\mathrm{Ca}_{\mathrm{V}} 1.2$-expressing cells (as in A-D). In both cases (Cav1.3 and $\left.\mathrm{Ca}_{\mathrm{V}} 1.2\right)$, MDIMP accelerated the rate of $\mathrm{I}_{\mathrm{Ca}}$ inactivation [(D and F), Supplemental Fig. 3]. 


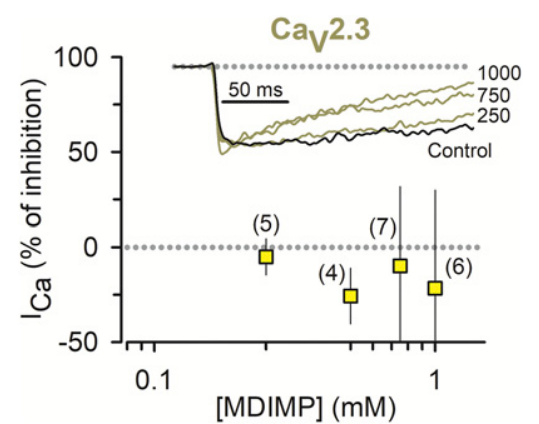

Fig. 2. Effects on $\mathrm{Ca}_{\mathrm{v}} 2.3$ channels. Average values of peak $\mathrm{I}_{\mathrm{Ca}}$ expressed as a percentage of inhibition by different concentrations of MDIMP. The inset shows examples of current traces carried by $\mathrm{Ca}_{\mathrm{V}} 2.3$, which were used to obtain the concentration-response curve. Rather than being reduced, the peak $\mathrm{I}_{\mathrm{Ca}}$ showed a tendency to be increased in response to MDIMP. Additionally, the compound promoted an acceleration on the kinetics of current decay (see also Supplemental Fig. 3). The results were obtained and analyzed as in Fig. 1.

to an essential methodological difference: in the previous study, a depolarized HP of $-50 \mathrm{mV}$ was used. Below, we will come back to this point.

Next, we focused on $\mathrm{Ca}_{V} 2.3$, an HVA R-type $\mathrm{Ca}^{2+}$ channel (Fig. 2). In comparison with results from L-type $\mathrm{Ca}^{2+}$ channels (Fig. 1), MDIMP did not reduce the peak $\mathrm{I}_{\mathrm{Ca}}$ of $\mathrm{Ca}_{\mathrm{V}} 2.3$, even at the highest concentration tested (i.e., $1 \mathrm{mM}$ ). Nevertheless, the kinetics of $\mathrm{I}_{\mathrm{Ca}}$ revealed a fascinating aspect: the rate of inactivation was drastically accelerated in a concentrationdependent manner (Fig. 2, inset). Accordingly, the compound exerted a marked inhibition at the end of the test pulse (i.e., 200 milliseconds), with an $\mathrm{IC}_{50}$ of $717 \mu \mathrm{M}$ (Supplemental Fig. 2).

Indeed, a similar effect on the inactivation rate of L-type $\mathrm{Ca}^{2+}$ channels was also observed [see, for example, the representative traces of Fig. 1 and those of Santamaria-Herrera et al. (2016)]. Moreover, by analyzing the $\mathrm{I}_{\mathrm{Ca}}$ remaining at the end of the test pulse, the $\mathrm{IC}_{50}$ values obtained from the data in Fig. 1 were smaller than those estimated from the peak $\mathrm{I}_{\mathrm{Ca}}$. Specifically, they range from 957 to $290 \mu \mathrm{M}\left(\mathrm{Ca}_{V} 1.3\right)$ and from 656 to $<250 \mu \mathrm{M}$ (Ca 1.2 ; Supplemental Fig. 2). The kinetics of inactivation were also studied by fitting exponential equations to the decaying phase of the current. In the case of $\mathrm{Ca}_{\mathrm{V}} 1.3$, a second-order exponential was necessary, whereas a firstorder exponential sufficed in both $\mathrm{Ca}_{\mathrm{v}} 1.2$ and $\mathrm{Ca}_{\mathrm{V}} 2.3$. In general, MDIMP reduced the value of time constants by $\sim 50 \%-60 \%$ (except for a fast component of $\sim 10$ milliseconds in $\mathrm{Ca}_{\mathrm{V}}$ 1.3, which was not altered; Supplemental Fig. 3). Thus, MDIMP accelerates the rate of inactivation in all $\mathrm{HVA} \mathrm{Ca}^{2+}$ channels, in spite of this process arising from distinct levels of complexity among channel subtypes.

Previous work in atrial myocytes showed that MDIMP preferentially inhibits $\mathrm{LVA} \mathrm{Ca}^{2+}$ currents $\left(\mathrm{I}_{\mathrm{CaLVA}}\right)$, suggesting a selective effect on $\mathrm{Ca}_{\mathrm{V}} 3$ channels (Santamaria-Herrera et al., 2016). In that work, however, this effect was not pursued further because the amplitude of cardiac $\mathrm{I}_{\mathrm{CaLVA}}$ is minimal ( $30 \mathrm{pA})$. Thus, we aimed to investigate whether MDIMP effectively inhibits $\mathrm{LVA} \mathrm{Ca}^{2+}$ channels with a higher potency than that observed for HVA channels. Figure 3A shows examples of $\mathrm{I}_{\mathrm{Ca}}$ that were obtained for $\mathrm{Ca}_{\mathrm{V}} 3.2$ in the absence and presence of MDIMP (250 and $500 \mu \mathrm{M})$. The time course of average $\mathrm{I}_{\mathrm{Ca}}$ values is also shown in Fig. 3B. It can be observed that MDIMP rapidly downregulates $\mathrm{Ca}_{\mathrm{v}} 3.2$ in approximately
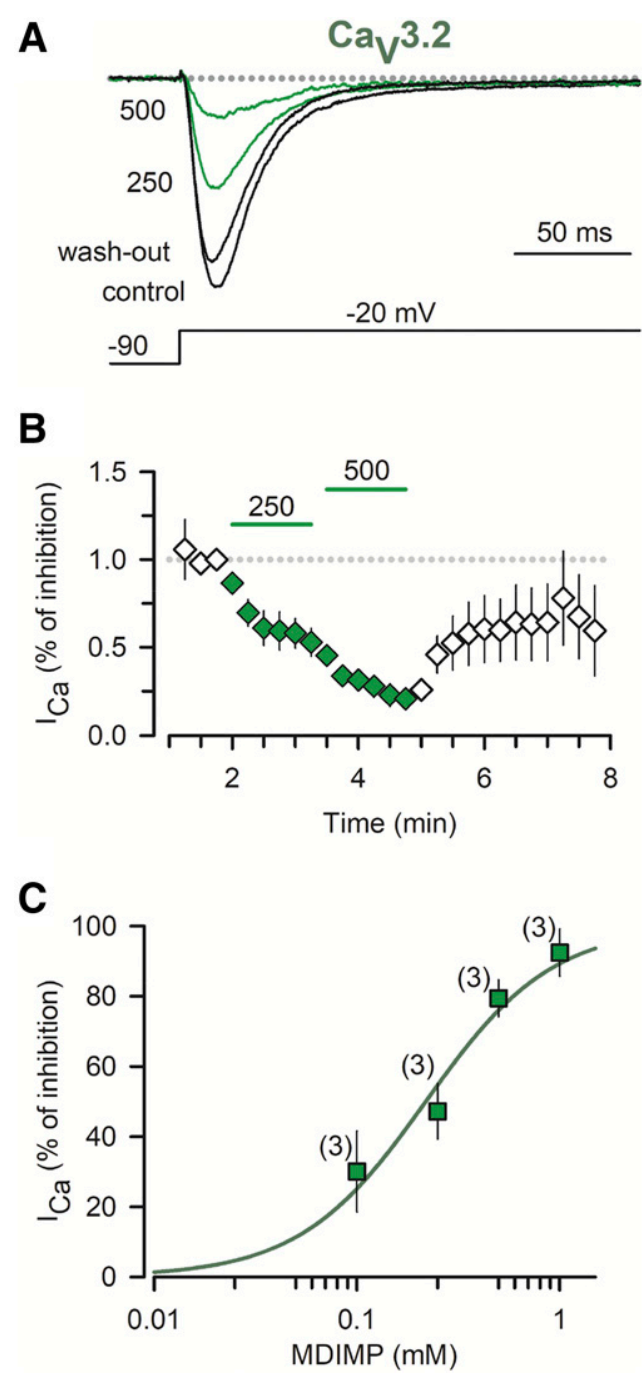

Fig. 3. MDIMP effects on Cav3.2 channels. (A) Representative traces of $\mathrm{I}_{\mathrm{Ca}}$ that were recorded in a Cav3.2-expressing cell in the absence (control), presence, and washout of MDIMP (250 and $500 \mu \mathrm{M})$. (B) Time course of average values of $\mathrm{I}_{\mathrm{Ca}}$ [recorded as in $\left.(\mathrm{A}), n=3\right]$. (C) Concentration-response curve obtained from experiments as in (A and $\mathrm{B}$ ). The green and open symbols indicate the presence and absence of MDIMP, respectively.

30 seconds. Notably, 250 and $500 \mu \mathrm{M}$ of MDIMP exert an inhibition of $\sim 45 \%$ and $\sim 80 \%$, respectively. Thus, after analyzing the entire concentration-response curve, it was possible to conclude that MDIMP inhibits $\mathrm{Ca}_{\mathrm{v}} 3.2$ with an $\mathrm{IC}_{50}$ of $\sim 220 \mu \mathrm{M}$, corroborating the idea that MDIMP preferentially acts on Cav3 channels. This conclusion was further supported by results obtained for $\mathrm{Ca}_{\mathrm{V}} 3.1$, as this channel exhibited the highest sensibility to MDIMP (Fig. 4). For example, the percentages of inhibition were, approximately, $75 \%$ and $95 \%$ for 250 and $500 \mu \mathrm{M}$. Accordingly, the $\mathrm{IC}_{50}$ was $\sim 130 \mu \mathrm{M}$ (the lowest among all $\mathrm{Ca}^{2+}$ channel types that we have investigated).

It is also worth noting that MDIMP did not promote changes in the kinetic properties of $\mathrm{Ca}_{\mathrm{V}} 3$ channels (Fig. 3A; Fig. 4A, see also Supplemental Fig. 4), which is in striking contrast with results obtained from $\mathrm{HVA} \mathrm{Ca}^{2+}$ channels. In the latter, the time course of inactivation was drastically accelerated (as described above and also shown in representative traces of Figs 1,2). Thus, MDIMP promotes "inactivation" but only in those channels exhibiting slow inactivation (i.e., HVA channels). 

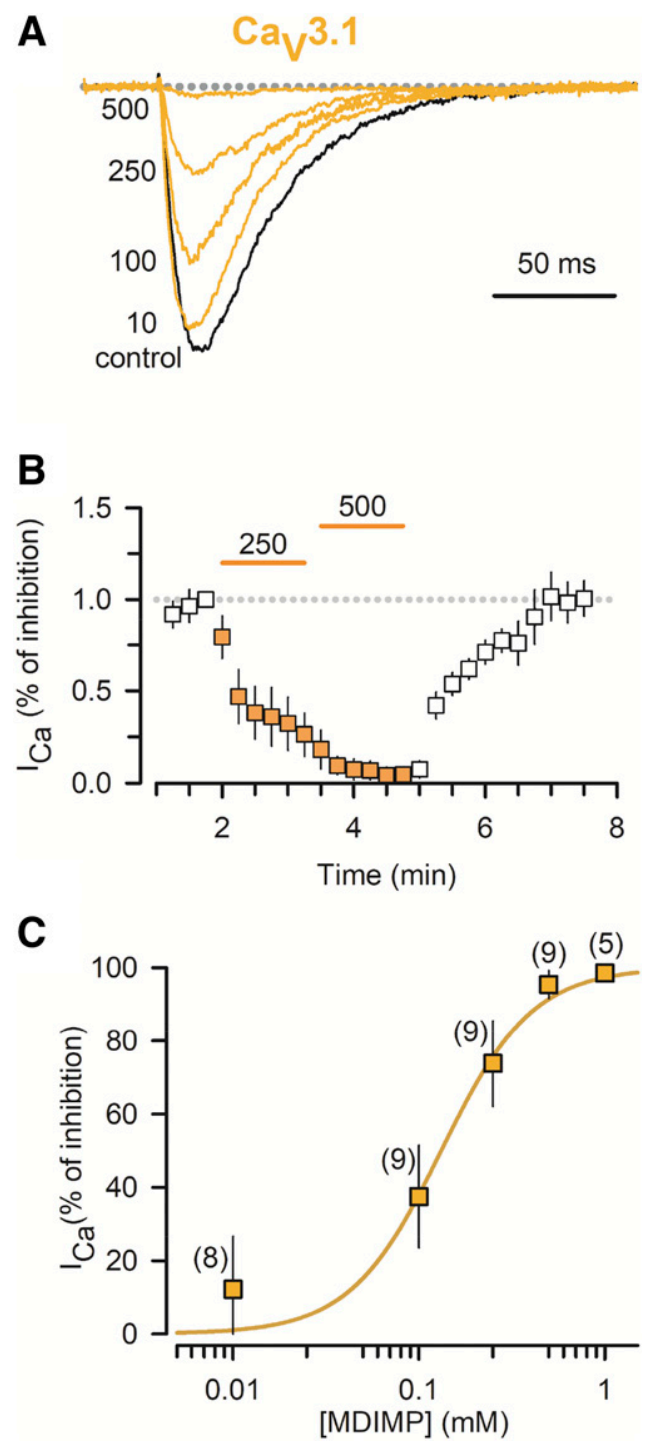

Fig. 4. MDIMP effects on Ca 3.1 channels. (A-C) Recordings of $\mathrm{I}_{\mathrm{Ca}}$ carried through Cav3.1 in the absence and presence of distinct molarities (micromolars) of MDIMP (A) and corresponding time course of inhibition (B) and concentration-response curve (C). Data were obtained as described in Fig. 3. The orange and open symbols indicate the presence and absence of MDIMP, respectively.

It is well known that many drugs exert their effects depending on conformational states of the channels, and thus their modulatory actions depend indirectly on $\mathrm{V}_{\mathrm{m}}$. In the next section, therefore, we investigated the voltage dependence of inactivation of $\mathrm{Ca}^{2+}$ channels in the presence and absence of MDIMP. The corresponding data are shown and summarized in Fig. 5 and Table 1. In all channel types, the isoindoline shifted the steady-state inactivation curve toward more negative membrane potentials, suggesting that the inactivated state facilitates MDIMP binding or vice versa. The extent of this effect, however, is somewhat variable. More specifically, the shift in $\mathrm{V}_{1 / 2}$ values is close to $-20 \mathrm{mV}$ for both T- $\left(\mathrm{Ca}_{\mathrm{V}} 3.1, \mathrm{Ca}_{\mathrm{V}} 3.2\right)$ and L-type $\mathrm{Ca}$ channels $\left(\mathrm{Ca}_{\mathrm{V}} 1.2\right.$ and $\mathrm{Ca}_{\mathrm{V}}$ 1.3), whereas $\mathrm{Ca}_{\mathrm{V}} 2.3$ exhibits the most considerable shift (of approximately $-40 \mathrm{mV}$; Fig. 5; Table 1). Indeed, the shape of inactivation curves was also significantly altered, but not in all types of channels. In particular, the $\mathrm{k}$ value was decreased for $\mathrm{Ca}_{v} 1.2$ and increased for both $\mathrm{Ca}_{\mathrm{v}} 3.1$ and $\mathrm{Ca}_{\mathrm{v}} 3.2$ (in all cases, the change in $\mathrm{k}$ was close to $5 \mathrm{mV}$; Fig. 5 ; Table 1 ).

In Fig. 6, the view that MDIMP preferentially binds to the inactivated state was further challenged for HVA channels. In particular, the MDIMP effects were now assessed from an HP of $-50 \mathrm{mV}$ (a potential that allows transitions from closed to inactivated states; see Fig. 5). The corresponding $\mathrm{IC}_{50}$ values were (in micromolars) 445 (Cav1.2), $231\left(\mathrm{Ca}_{\mathrm{V}} 1.3\right)$, and 557 $\left(\mathrm{Ca}_{\mathrm{V}} 2.3\right)$; that is, much smaller than those observed with an $\mathrm{HP}$ of $-90 \mathrm{mV}$ (compare data of Fig. 6A with those of Figs. 1 and 2). These data reinforce our conclusion that MDIMP preferentially binds to VGCCs in the inactivated state. Besides, similar to the observed with an $\mathrm{HP}$ of $-90 \mathrm{mV}$, the $\mathrm{IC}_{50}$ values are also smaller if the $\mathrm{I}_{\mathrm{Ca}}$ is assessed at the end of 200-millisecond pulses (Fig. 6B and inset).

Data showed in Fig. 6 suggest that an HP of $-50 \mathrm{mV}$ may help MDIMP to discriminate between $\mathrm{Ca}_{\mathrm{V}} 1.2$ and $\mathrm{Ca}_{\mathrm{V}} 1.3$ channels; the $\mathrm{IC}_{50}$ of the former nearly doubles that of the latter (Fig. 6). Thus, we decided to re-examine the effects of $250 \mu \mathrm{M}$ MDIMP on these two types of calcium channels over an extended time scale ( $\sim 10$ minutes, as opposed to the typical 90 -second applications). The data obtained from this experimental series are summarized in Fig. 7. In keeping with the results of Fig. 6A, 90 seconds of MDIMP application caused a notable inhibition of $\mathrm{Ca}_{\mathrm{V}} 1.3$ (by approximately $60 \%$ ), whereas Cav1.2 was barely affected $(\sim 7 \%)$. Moreover, although in both channel types the extent of inhibition continued growing, $\mathrm{Ca}_{\mathrm{V}} 1.3$ showed the higher rate $(\tau=1.55$ minutes, vs. $\tau=4.94$ minutes), and by 10 minutes, the fraction of inhibition was 0.93 $\left(\mathrm{Ca}_{\mathrm{V}}\right.$ 1.3) and 0.43 (Cav1.2). Thus, $250 \mu \mathrm{M}$ MDIMP indeed helps to distinguish between $\mathrm{Ca}_{\mathrm{V}} 1.2$ and $\mathrm{Ca}_{\mathrm{V}} 1.3$.

We next wondered whether MDIMP can also bind to the closed state of VGCCs, and this point was investigated for $\mathrm{Ca}_{\mathrm{V}} 2.3$ (Fig. 8) and the two types of LVA channels (i.e., $\mathrm{Ca}_{\mathrm{V}} 3.1$ and $\mathrm{Ca}_{\mathrm{V}} 3.2$; Supplemental Fig. 5). The experiment consisted in keeping the channels closed; that is, at an $\mathrm{HP}$ of $-90 \mathrm{mV}$ but exposed to MDIMP for a couple of minutes. Then, the percentage of effect on $\mathrm{I}_{\mathrm{Ca}}$ was assessed at the first depolarizing pulse. In the case of $\mathrm{Ca}_{\mathrm{V}} 2.3$, the action of the isoindoline was somewhat complex. A small increase in peak $\mathrm{I}_{\mathrm{Ca}}$ (of 13\%) preceded a slight reduction in the magnitude of current remaining at 200 milliseconds (of $21 \%$ ), and a striking change in current kinetics reflected these two effects (Fig. 8). Accordingly, the compound promoted a 2 -fold increase in the fraction of inactivation (i.e., from $0.25 \pm 0.09$ to $0.50 \pm 0.10 ; P=0.005$ ). These data suggest that the closed state of the Cav2.3 HVA channel binds MDIMP, and this results in marked alterations in gating. Moreover, MDIMP also acts on the closed state of $\mathrm{Ca}_{\mathrm{V}} 3.1$ and $\mathrm{Ca}_{\mathrm{V}} 3.2$ channels, as evidenced by results from a similar protocol as in Fig. 8, showing a significant reduction in the peak $\mathrm{I}_{\mathrm{Ca}}$ (of $39 \%$ and $26 \%$, respectively; Supplemental Fig. 5). Thus, we conclude that the MDIMP binds to VGCCs not only in the inactivated (Fig. 5) state but also in the closed one.

We next focused on activation curves. In these experiments, the $\mathrm{HVA} \mathrm{Ca}{ }^{2+}$ channels were examined from an $\mathrm{HP}$ of $-50 \mathrm{mV}$ to facilitate inhibition. As can be seen in Fig. 9, MDIMP promoted significant reductions on the maximal conductance $\left(\mathrm{G}_{\max }\right)$ of all channel types. In contrast, the slope factor $(\mathrm{k})$ and midpoint $\left(\mathrm{V}_{1 / 2}\right)$ were in general unaltered: the only exception was for $\mathrm{Ca}_{\mathrm{V}} 1.3$ and $\mathrm{Ca}_{\mathrm{V}} 2.3$, whose $\mathrm{V}_{1 / 2}$ values were shifted by nearly $-4 \mathrm{mV}$ (Fig. 9; Table 1). 

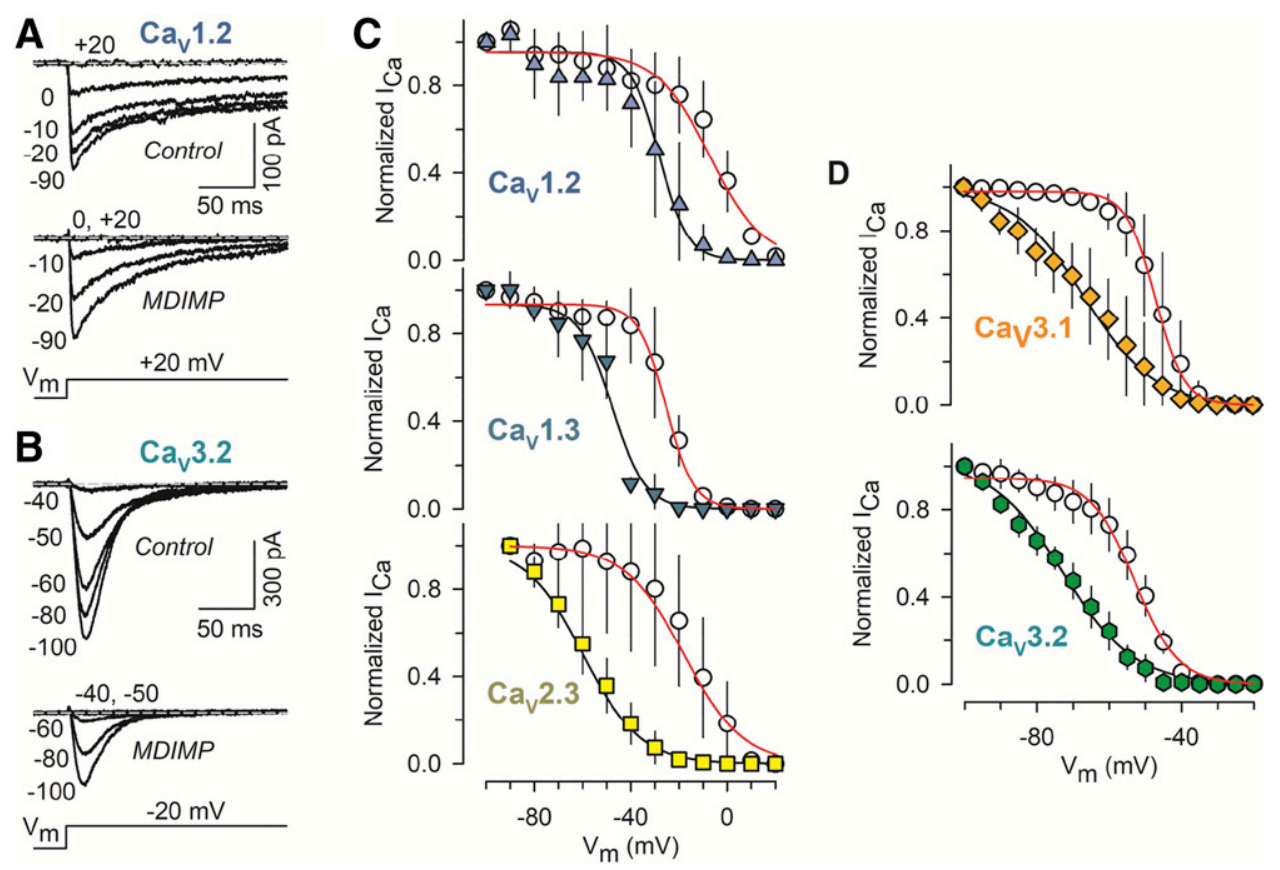

Fig. 5. The MDIMP shifts the voltage dependence of inactivation toward more negative potentials. (A and B) Representative current traces that were used to investigate the steady-state voltage dependence of inactivation in the absence (Control) and presence of MDIMP. A 5-second prepulse to distinct membrane potentials $\left(\mathrm{V}_{\mathrm{m}}\right)$ preceded test pulses to either $+20 \mathrm{mV}$ [(A) HVA channels] or $-20 \mathrm{mV}$ [(B) LVA channels]. (C and D) Average inactivation curves that were obtained from recordings as in (A and B). The circles represent Control conditions, whereas colored symbols indicate the presence of MDIMP. For each data set, the peak $\mathrm{I}_{\mathrm{Ca}}$ was normalized to its maximum value and plotted as a function of prepulse potential, and the resulting inactivation curves were fitted according to a Boltzmann equation (eq. 2). The corresponding parameters are given in Table 1, and their mean values were used to calculate the smooth lines. Results are from a total of four to five investigated cells (per channel type). The MDIMP concentration was (in micromolars) 130 (Cav3.1), 220 (Cav3.2), 500 (Cav1.2 and $\mathrm{Ca}_{\mathrm{V}} 2.3$ ), and 1000 (Cav1.3). Open circles - Control, upward triangles - Ca 1.2 , downward triangles - Cav1.3, squares - Cav2.3, diamonds - Cav3.1, hexagonal symbols - Cav3.2.

Thus far, $\mathrm{Ca}_{\mathrm{v}} 3.1$ is the channel with the highest affinity for MDIMP. This finding, combined with a previous suggestion that MDIMP binds to the selectivity filter of VGCCs (MancillaPercino et al., 2010), motivated us to investigate whether substituting amino acids of the selectivity filter of $\mathrm{Ca}_{\mathrm{v}} 3.1$ modifies the affinity for MDIMP. In particular, we studied the following point mutations: DEDD and DDDD (Garza-López et al., 2016). The corresponding results are shown in Fig. 10A (representative traces) and Fig. 10B (concentration-response curves). It can be observed that MDIMP inhibited the activity of both mutant proteins, but the inhibition occurred at concentrations higher than those observed for the wild-type channel. For example, the mutant proteins were barely affected by 100 and $250 \mu \mathrm{M}$ (Fig. 10), whereas these concentrations inhibited the wild-type channel by approximately $40 \%$ and 80\% (Fig. 10, dashed line; see also Fig. 4). These results are in line with the view that the selectivity filter of VGCCs represents an important domain for MDIMP binding.

To obtain more insight about a possible pore-blocking mechanism, we decided to determine whether the ions flowing in the outward direction may unplug the $\mathrm{Ca}_{\mathrm{v}} 3.1$ channel (possibly by removing MDIMP from its putative binding site in the selectivity filter). However, under our standard $\mathrm{I}_{\mathrm{Ca}}$ recording conditions, depolarizations to 80 and $100 \mathrm{mV}$ were unable to elicit a possible efflux of $\mathrm{Cs}^{+}$through Cav3.1. Therefore, we decided to study an outward $\mathrm{Na}^{+}$current instead, using a protocol described elsewhere (Fig. 11; Lopin et al., 2012). The corresponding results indicate that this current is reduced to a $\sim 50 \%$ in the presence of

TABLE 1

Parameters of fitted steady-state inactivation and I-V curves

\begin{tabular}{|c|c|c|c|c|c|c|c|c|}
\hline & & \multicolumn{3}{|c|}{ Steady-State Inactivation-V Data } & \multicolumn{4}{|c|}{ I-V Data } \\
\hline & & $\mathrm{V}_{1 / 2}(\mathrm{mV})$ & $\mathrm{k}(\mathrm{mV})$ & $n$ & $\mathrm{~V}_{1 / 2}(\mathrm{mV})$ & $\mathrm{k}(\mathrm{mV})$ & $\mathrm{V}_{\text {rev }}(\mathrm{mV})$ & $n$ \\
\hline \multirow[t]{2}{*}{$\mathrm{Ca}_{V} 1.2$} & Control & $-7.3 \pm 5.4$ & $11.0 \pm 4.0$ & 5 & $13.7 \pm 4.3$ & $7.7 \pm 0.9$ & $81.4 \pm 5.0$ & 8 \\
\hline & MDIMP & $-28.3 \pm 9.4^{*}$ & $5.9 \pm 1.8^{*}$ & & $12.9 \pm 4.9$ & $7.9 \pm 0.8$ & $77.9 \pm 5.5$ & \\
\hline \multirow[t]{2}{*}{$\mathrm{Ca}_{\mathrm{V}} 1.3$} & Control & $-25.3 \pm 6.0$ & $5.7 \pm 1.7$ & 5 & $4.4 \pm 3.4$ & $7.1 \pm 0.7$ & $71.8 \pm 5.1$ & 4 \\
\hline & MDIMP & $-47.7 \pm 9,9^{*}$ & $6.9 \pm 4.3$ & & $0.5 \pm 3.4^{*}$ & $6.7 \pm 0.4$ & $70.3 \pm 6.1$ & \\
\hline \multirow[t]{2}{*}{$\mathrm{Ca}_{\mathrm{V}} 2.3$} & Control & $-17.9 \pm 9.1$ & $12.2 \pm 7.6$ & 5 & $21.4 \pm 4.2$ & $7.0 \pm 0.4$ & $86.8 \pm 8.6$ & 7 \\
\hline & MDIMP & $-59.7 \pm 7.8^{*}$ & $11.8 \pm 3.4$ & & $17.2 \pm 5.0^{*}$ & $7.5 \pm 0.9$ & $85.7 \pm 5.9$ & \\
\hline \multirow[t]{2}{*}{$\mathrm{Ca}_{\mathrm{V}} 3.1$} & Control & $-46.9 \pm 5.1$ & $4.0 \pm 0.6$ & 4 & $-20.7 \pm 4.5$ & $5.3 \pm 1.4$ & $50.0 \pm 6.9$ & 4 \\
\hline & MDIMP & $-66.6 \pm 10.1^{*}$ & $9.7 \pm 2.2^{*}$ & & $-22.6 \pm 2.4$ & $5.1 \pm 0.9$ & $47.3 \pm 12.0$ & \\
\hline \multirow[t]{2}{*}{$\mathrm{Ca}_{\mathrm{v}} 3.2$} & Control & $-53.0 \pm 2.8$ & $6.0 \pm 1.2$ & 4 & $-23.4 \pm 5.4$ & $5.5 \pm 1.8$ & $55.7 \pm 2.8$ & 3 \\
\hline & MDIMP & $-72.8 \pm 4.6^{*}$ & $9.9 \pm 0.7^{*}$ & & $-25.8 \pm 3.9$ & $5.8 \pm 1.2$ & $57.2 \pm 5.3$ & \\
\hline
\end{tabular}


A
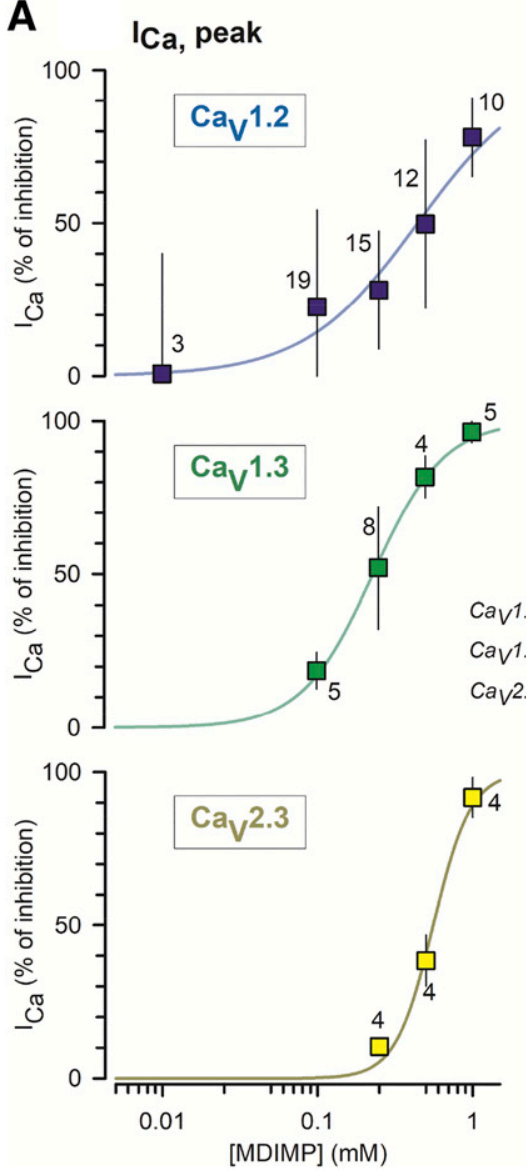

B

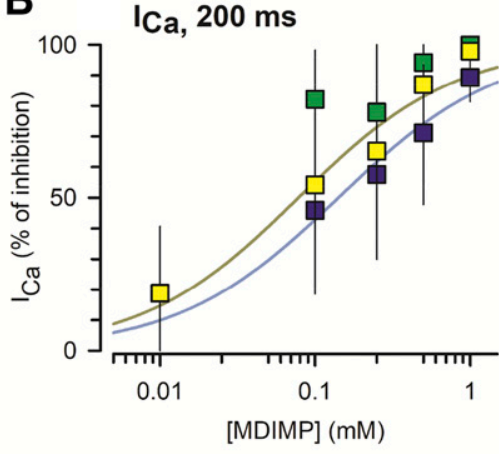

$I C_{50}(\mu M)$

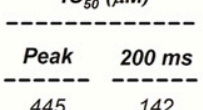

$231<100$

$557 \quad 78$

C

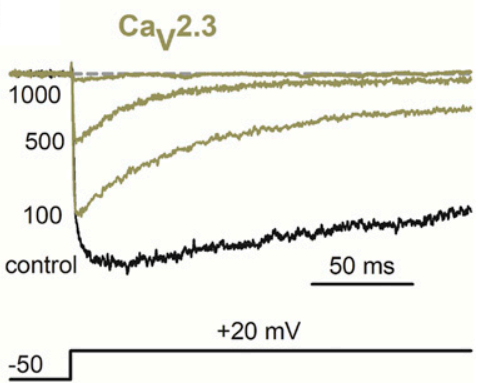

Fig. 6. A depolarized HP increases the sensitivity of HVA $\mathrm{Ca}^{2+}$ channels to MDIMP. (A) Percentage of peak $\mathrm{I}_{\mathrm{Ca}}$ inhibition as a function of MDIMP concentration. $\mathrm{I}_{\mathrm{Ca}}$ was elicited as described in Figs. 1 and 2 but using an HP of $-50 \mathrm{mV}$. (B) Same data as in (A), except that $\mathrm{I}_{\mathrm{Ca}}$ was measured 200 milliseconds after test pulse onset. (C) Examples of current traces that were recorded in presence of distinct MDIMP concentrations (numbers, in micromolars) and then used to analyze the degrees of inhibition showed in (A and B). The inset illustrates $\mathrm{IC}_{50}$ values that were obtained using either the peak magnitude of $\mathrm{I}_{\mathrm{Ca}}$ or the current remaining at 200 milliseconds. The purple, green, and yellow squares indicate data obtained for the Cav1.2, Cav1.3, and Cav2.3 channels, respectively.
$130 \mu \mathrm{M}$ MDIMP (Fig. 11, A and C). This effect is in agreement with the data of Figs. 4 and 9 , in which the $\mathrm{IC}_{50}$ for $\mathrm{I}_{\mathrm{Ca}}$ reduction was about $130 \mu \mathrm{M}$.

Moreover, MDIMP reduced the magnitude of both outward and inward (tail) currents to a similar extent in the same pool of cells (Fig. 11C). The similarity of effects on inward and outward currents suggests that a driving force for the efflux of ions fails in releasing the MDIMP-Cav3.1 interaction. Unfortunately, this result does not support the pore-blocking hypothesis.

Figure 11 also shows instantaneous I-V curves that were obtained by analyzing the initial amplitude of the tail current (Fig. 11, A and B). It can be observed that MDIMP did not alter the shape of the normalized curves (Fig. 11B, inset), indicating that the effect on a single channel is all-or-none (according to the terminology of Armstrong, 1971).

\section{Discussion}

In this work, we studied the regulation of cardiac VGCCs by MDIMP, a novel inhibitor of both calcium channels and EC coupling, with atrial selectivity. Indeed, a previous study showed that MDIMP preferentially acts on LVA calcium currents of atrial myocytes, suggesting that $\mathrm{Ca}_{\mathrm{V}} 3$ channels exhibit the highest affinity for this compound (SantamariaHerrera et al., 2016). In these cells, the LVA calcium current is thought to reflect the activity not only of $\mathrm{Ca}_{\mathrm{V}} 3$ channels (i.e., $\mathrm{Ca}_{\mathrm{v}} 3.1$ and $\mathrm{Ca}_{\mathrm{v}} 3.2$ ) but also Cav1.3 and Cav2.3 (PiedrasRentería et al., 1997; Larsen et al., 2002; Zhang et al., 2005;
Ríos-Pérez et al., 2016). Thus, the present study represents the first unequivocal demonstration that MDIMP preferentially binds to $\mathrm{Ca}_{\mathrm{V}} 3$ channels. In addition, our data suggest that the compound regulates these channels by acting in all-or-none fashion (for the instantaneous I-V curves have the same shape in the absence and presence of MDIMP).

Moreover, apart from describing the molecular and biophysical properties of the regulation, our study investigated the hypothesis that the selectivity filter represents the highaffinity receptor site for MDIMP. Indeed, evidence in favor of this view was obtained as the mutations of the selectivity filter decreased the affinity for the compound. Nevertheless, the pore-blocking model could not be supported by analyzing effects on outward currents. Thus, further investigation is needed to more firmly establish the precise mechanism.

Below, we discuss tentative mechanisms for the inhibition as well as the possible pharmacological and clinical relevance of MDIMP. From now on, the term "blockade" is used to indicate that MDIMP might bind within the selectivity filter of the channels. On the other hand, "modulation" (i.e., inhibition or stimulation), is reserved to imply that the MDIMP can bind to either the pore or an alternative site, resulting in allosteric consequences (i.e., alterations in gating).

Mechanisms of MDIMP Effects on VGCCs. The functional properties of a VGCC emerge from the movement of many segments in at least one of the proteins that form the channel (i.e., main subunit). Thus, when a compound binds to an ion channel, it seems reasonable to expect that the function of the latter might be modified. The influence of the pore 

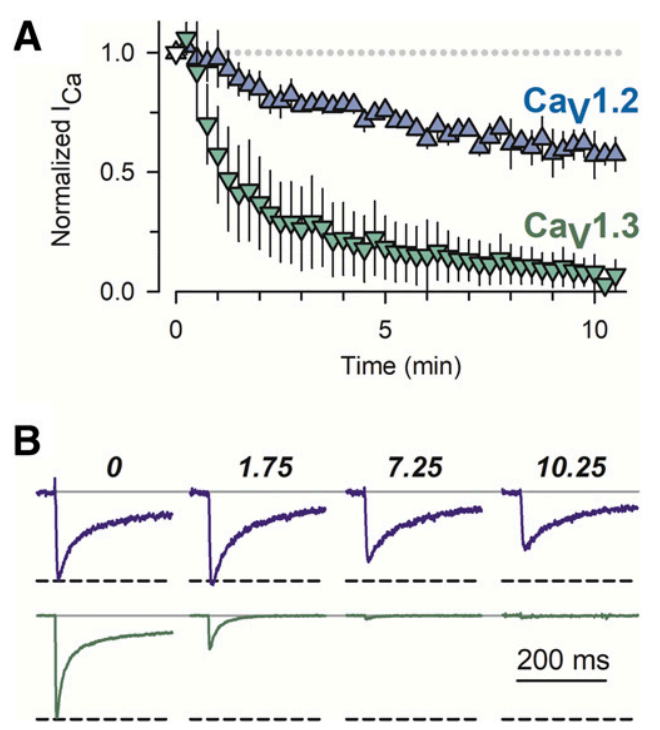

Fig. 7. MDIMP discriminates between $\mathrm{Ca}_{\mathrm{V}} 1.2$ and $\mathrm{Ca}_{\mathrm{V}} 1.3$. (A) Normalized $\mathrm{I}_{\mathrm{Ca}}$ values obtained from $\mathrm{Ca}_{\mathrm{V}} 1.2$ - and $\mathrm{Ca}_{\mathrm{v}} 1$.3-expressing cells in either absence (open symbols) or presence of $250 \mu \mathrm{M}$ MDIMP (colored symbols). Test pulses (to $+20 \mathrm{mV}$ ) were applied from an $\mathrm{HP}$ of $-50 \mathrm{mV}$, and data represent the means \pm S.D. from three cells per experimental condition. (B) Examples of $\mathrm{I}_{\mathrm{Ca}}$ traces that were analyzed to generate the results shown in (A). The numbers indicate the time in presence of MDIMP (minutes). Blue symbols/traces $-\mathrm{Ca}_{\mathrm{V}} 1.2$, green symbols/traces $-\mathrm{Ca}_{\mathrm{V}} 1.3$

region on functional properties is not exempt from this principle. On the contrary, there are examples in which pharmacological or molecular modifications of the pore result in significant functional effects. The pore blockade of $\mathrm{Na}^{+}$ channels by $\mathrm{Ca}^{2+}$, which also shifts the open probability toward more positive potentials, is an emblematic example (Armstrong and Cota, 1991). Besides, it was recently shown that substituting a single amino acid, located next to the glutamate that belongs to the selectivity filter of human $\mathrm{Ca}_{\mathrm{V}} 1.2$ (located in domain $\mathrm{II}$ ), eliminates $\mathrm{Ca}^{2+}$-dependent inactivation, a process that begins intracellularly with allosteric modulation (by $\mathrm{Ca}^{2+}$ and calmodulin) of the $\mathrm{COOH}-$ terminal domain (Abderemane-Ali et al., 2019). Moreover, it has been reported that the point mutations of the selectivity filter significantly alter the gating of $\mathrm{Ca}_{\mathrm{v}} 3.1$ (Talavera et al., 2003). Thus, although the pore-blocking mechanism would seem to represent the most straightforward explanation to the finding that the potency of MDIMP varies with the selectivity filter configuration, it is also possible that, instead, the latter exerts a remote control on another binding site.

Currently, it is difficult to explain the apparent paradox that, under certain circumstances, a $\mathrm{Ca}^{2+}$ channel antagonist also elicits a significant increase in the activity of the channels. Something roughly similar has been reported for DHPs (e.g., Bean, 1985), and the explanation relies on using racemic mixtures and the well known agonist and antagonist actions of DHP stereoisomers. In our study, however, this explanation can be ruled out because the MDIMP was obtained from pure L-leucine. Indeed, we have also synthesized the D enantiomer ((R)-MDIMP, Supplemental Fig. 1) to assess its potential to inhibit $\mathrm{Ca}_{\mathrm{V}} 3$ channels. The results show that $\mathrm{Ca}_{\mathrm{V}} 3.2$ exhibits roughly the same affinity for both MDIMP and $(R)$-MDIMP (Supplemental Fig. 6). $\mathrm{Ca}_{\mathrm{V}} 3.1$, on the other hand, showed a slightly lower sensitivity to $(R)$-MDIMP (i.e., the $\mathrm{IC}_{50}$ was $\sim 260 \mu \mathrm{M}$, which is nearly 2 -fold higher than that of MDIMP; Supplemental Fig. 6). Accordingly, results from docking experiments indicate that the $(R)$-MDIMP has a lower affinity for the pore region of VGCCs compared with MDIMP (data not shown).

Shifting the steady-state inactivation curve toward more negative potentials was a common feature of MDIMP effects. This can be interpreted to suggest that in all channels, the inactivated state facilitates binding of MDIMP, either to the pore or to an alternative site, and thereby the inactivation also promotes the corresponding blockade or inhibition. Preferential binding of drugs to the inactivated state is frequently observed. The example of DHPs acting on Cav1 (L-type) channels is emblematic. For example, when the HP changes from -80 to $-15 \mathrm{mV}$ (i.e., from privileging the resting state to promoting inactivation), then the $\mathrm{IC}_{50}$ for the effect of nitrendipine dramatically decreases (up to $\sim 2000$-fold, from 730 to $0.36 \mathrm{nM}$; Bean, 1985). Another similitude between DHP antagonists and MDIMP is their ability to accelerate the inactivation rate of L-type $\mathrm{Ca}^{2+}$ channels (e.g., Bean, 1985; this study). Interestingly, it has been proposed that the DHPs bind to the lateral, lipid-facing side of the pore module, and this promotes an allosteric modification (asymmetry) of ion binding sites, which in turn results in high-affinity $\mathrm{Ca}^{2+}$ binding and blockade of the selectivity filter (Tang et al., 2016).
A

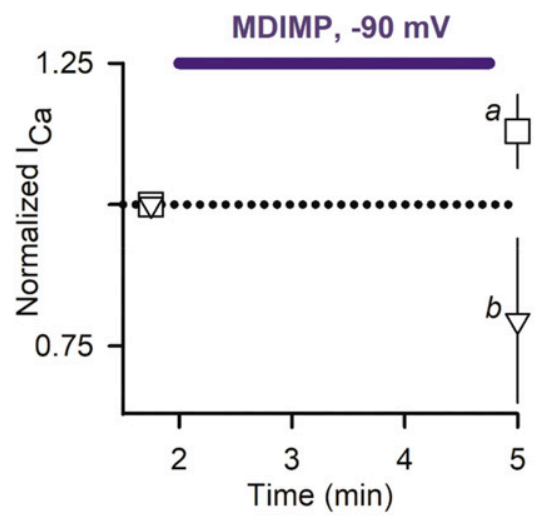

B
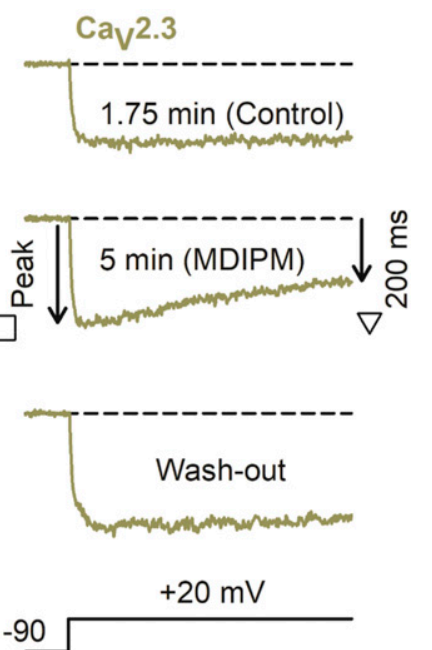

Fig. 8. MDIMP binds to the closed state of $\mathrm{Ca}_{\mathrm{v}} 2.3$. (A) Relative magnitude of $\mathrm{I}_{\mathrm{Ca}}$ that was estimated both at its maximum level (peak, squares) and the end (200 milliseconds, triangles) of test pulses before ( 1.75 minutes) and 3.25 minutes after MDIMP exposure. During the MDIMP application, the membrane potential was kept at $-90 \mathrm{mV}$ (i.e., in absence of depolarizing test pulses). Then, a train of pulses was delivered (15-second cycle length), followed by the washout of MDIMP $\left(\mathrm{I}_{\mathrm{Ca}}\right.$ measurements are shown only for the first pulse of the train, minute 5). ${ }^{a} P=0.011,{ }^{b} P=$ 0.034; compared with the corresponding control (1.75 minutes, $n=5$ ). (B) Representative current traces that were used to generate data of (A). 
A
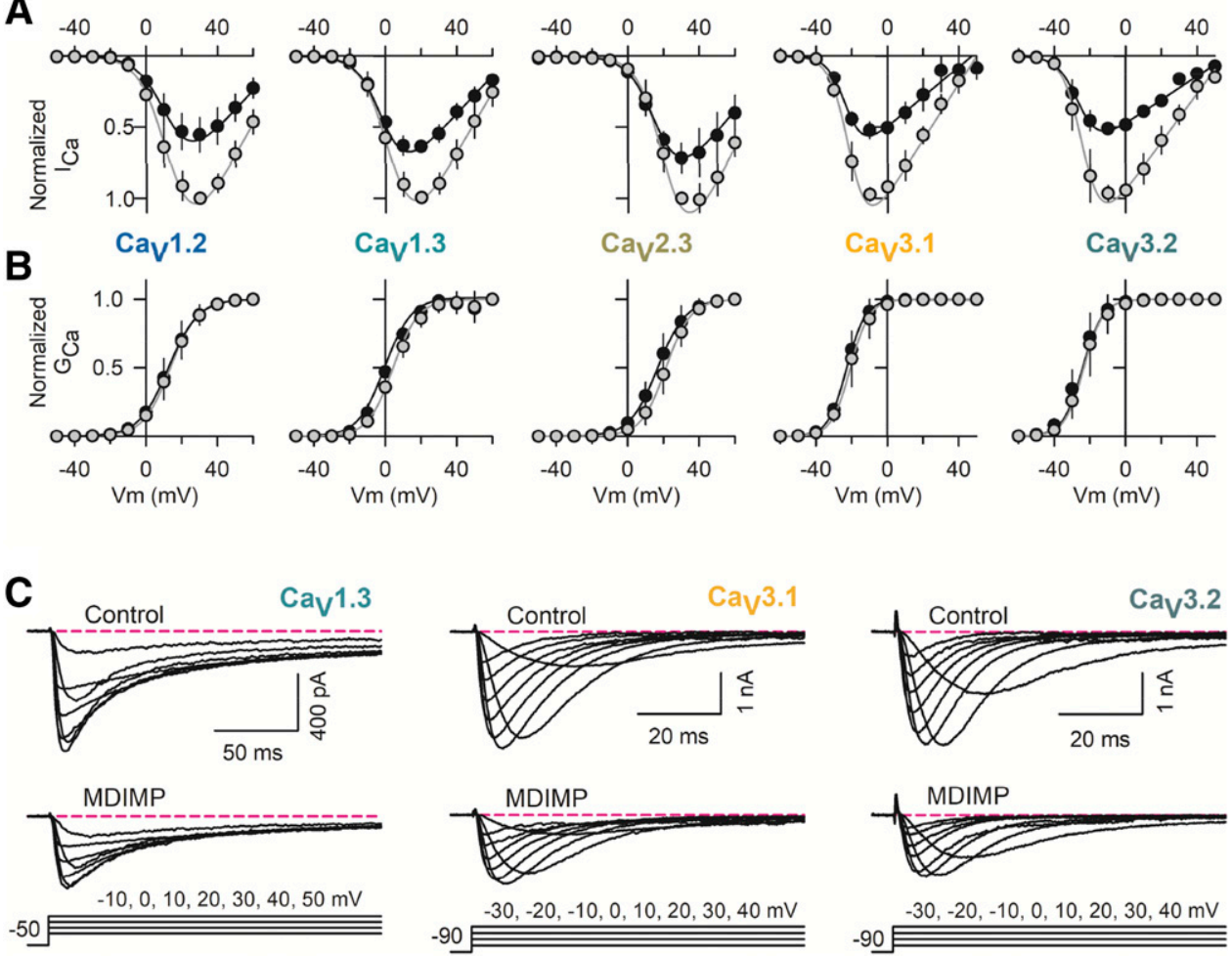

Fig. 9. MDIMP does not promote major changes in the voltage dependence of $\mathrm{Ca}^{2+}$ channel activation. (A) I-V curves obtained in the absence (gray symbols) and presence of MDIMP (closed symbols). The results were normalized to the maximum $\mathrm{I}_{\mathrm{Ca}}$ value observed in each particular cell in the absence of MDIMP. Subsequently, the I-V curves were fitted according to a Boltzmann equation (eq. 3). The resulting parameters and number of experiments are given in Table 1. (B) Activation curves that were estimated from the $\mathrm{I}_{\mathrm{Ca}}$ values shown in (A) and their corresponding Boltzmann parameters. The values of $\mathrm{Ca}^{2+}$ conductance $\left(\mathrm{G}_{\mathrm{Ca}}\right)$ were normalized to $G_{\max }$. (C) Examples of $\mathrm{I}_{\mathrm{Ca}}$ families that were used to generate the data of $(\mathrm{A}$ and $\mathrm{B})$. The concentration of MDIMP was (in micromolars) 500 (Cav1.2 and $\mathrm{Ca}_{\mathrm{v}} 2.3$ ), 230 (Cav1.3), 220 (Cav3.2), and 130 (Cav3.1).

A

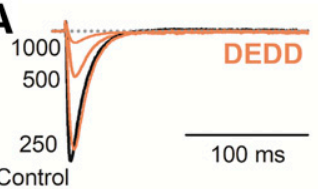
feedback loop.

2. The open state facilitates the blockade. This possibility arises from assuming that the movement of activation gates to the open position liberates access to a binding site located in the selectivity filter. A precedent exists for this mechanism regarding LVA channels and antiepileptic drugs (succinimides). More precisely, it has been reported that these drugs not only show a high affinity for the inactivated state but also accelerate the apparent inactivation rate of $\mathrm{I}_{\mathrm{CaLVA}}$. To investigate whether a possible pore-blocking mechanism explains these findings, Gomora et al. (2001) compared the percentage of effect on inward and outward currents and found that these compounds significantly alter

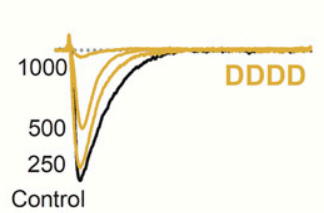
mutations, respectively. the influx of $\mathrm{Ca}^{2+}$ but have little impact on outward currents (carried through $\mathrm{Ca}_{\mathrm{v}} 3.3$ ). This unidirectional action was interpreted to suggest that succinimides indeed clog the pore. Moreover, it also indicates that the ions flowing in the outward direction unplug the channel (Gomora et al., 2001).

In the present study, we did not observe an unplug of $\mathrm{Ca}_{\mathrm{V}} 3.1$ channels by the outward current, despite the view that MDIMP might bind to the selectivity filter. Thus, the identification of the actual binding site(s) warrants further investigation.

Currently, it is hard to understand why an outward current failed to release the supposed interaction of MDIMP with an

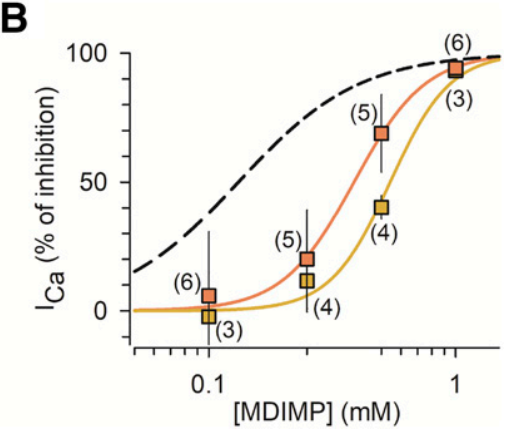

Fig. 10. Mutations in the selectivity filter of $\mathrm{Ca}_{\mathrm{v}} 3.1$ interfere with the affinity for MDIMP. (A) Calcium currents carried through Cav3.1 mutant channels (DEDD and DDDD) in the presence of distinct MDIMP concentrations (micromolars). (B) Concentration-response curves that were obtained from recordings as in (A); the estimated $\mathrm{IC}_{50}$ values are $387 \mu \mathrm{M}$ (DEDD) and $543 \mu \mathrm{M}$ (DDDD). A dashed line representing data gathered for the wild-type Cav3.1 is shown for comparison (see Fig. 4). The orange and yellow squares indicate data obtained for the DEDD and DDDD 

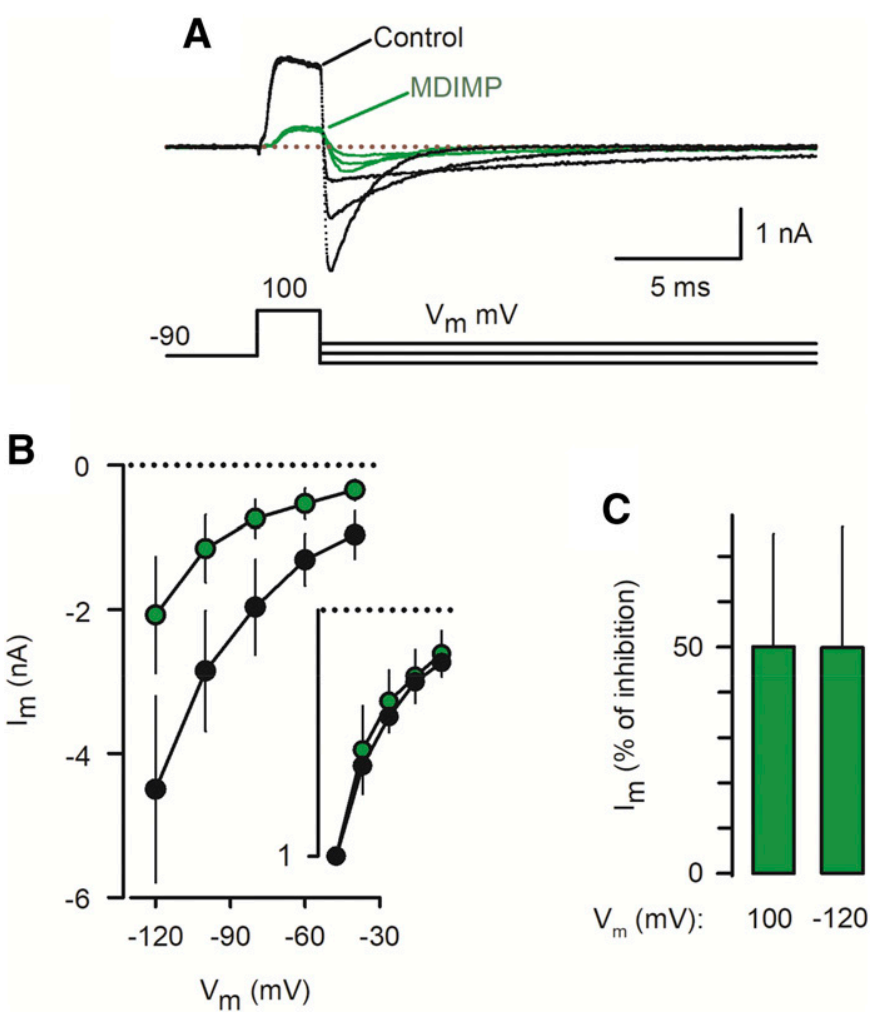

Fig. 11. An outward current cannot release the inhibition by MDIMP. (A) Experimental protocol and representative traces of ionic current $\left(\mathrm{I}_{\mathrm{m}}\right)$ used to compare MDIMP $(130 \mu \mathrm{M})$ effects on inward and outward currents. (B) Average values of $\mathrm{I}_{\mathrm{m}}$ that were obtained from tail currents as those shown in (A) as a function of $\mathrm{V}_{\mathrm{m}}$ (instantaneous I-V curves). The inset shows the same I-V curves but after dividing every data set by its corresponding value observed at $-120 \mathrm{mV}$. The decaying phase of tail currents was fitted to a single exponential equation, and $\mathrm{I}_{\mathrm{m}}$ represents an extrapolation to the time of repolarization. No significant differences were found among experimental groups regarding time constants for current decay (i.e., closing kinetics; data not shown). (C) Percentages of $\mathrm{I}_{\mathrm{m}}$ inhibition by MDIMP that were estimated at the indicated membrane potential. The results were obtained from five $\mathrm{Ca}_{\mathrm{V}} 3.1$-expressing cells, using the following recording solutions (in millimolars): $2 \mathrm{CaCl}_{2}, 128 \mathrm{NaCl}, 5$ ascorbic acid, 10 glucose, and $20 \mathrm{HEPES}$ (external); and $2 \mathrm{CaCl}_{2}, 1 \mathrm{MgCl}_{2}, 120 \mathrm{NaCl}, 10 \mathrm{HEPES}$ $4 \mathrm{MgATP}$, and $11 \mathrm{EGTA}$. In both cases, the $\mathrm{pH}$ was adjusted to 7.3 with $\mathrm{NaOH}$. The absence and presence of MDIMP is indicated by closed and green symbols, respectively.

outer pore domain. This apparent inconsistency could be explained by proposing that the interaction promotes a pore collapse. Under these circumstances, the intracellular ions would be trapped; that is, unable to pass through a collapsed pore, which represents a physical barrier for reaching-and expelling-MDIMP. Apart from serving as a conciliatory mechanism, this idea of "pore collapse" is consistent with our results suggesting that MDIMP acts in an all-or-none fashion (Fig. 11B).

Potential Pharmacological and Clinical Significance of MDIMP. The relevance of $\mathrm{Ca}_{\mathrm{v}} 3$ channels for the cardiac function is related to pacemaker depolarization, and thereby their blockade is thought to be cardioprotective in the context of atrial fibrillation. Besides, they can be re-expressed under certain pathological conditions as part of the neonatal program of gene expression. More generally, the $\mathrm{Ca}_{\mathrm{V}} 3$ channels participate in regulating the function of a number of cell types, including not only excitable but also nonexcitable cells (PerezReyes, 2003; Zamponi et al., 2015). Thus, a selective blockade of $\mathrm{Ca}_{\mathrm{V}} 3$ channels by MDIMP could be of therapeutic benefit. The finding that this compound preferentially inhibits EC coupling in atrial versus ventricular myocytes, combined with the fact that $\mathrm{Ca}_{\mathrm{V}} 3$ channels are only expressed in the former cells, indirectly supports this interpretation.

On the other hand, the affinity of $\mathrm{Ca}_{\mathrm{V}} 3$ channels for MDIMP is not higher than that found for other compounds. Indeed, certain compounds exert their effects with $\mathrm{IC}_{50}$ values in the low micromolar range (Perez-Reyes, 2003; Hashimoto and Kawazu, 2015). However, apart from selectivity, the tolerability is also essential for a compound to be clinically relevant. Therefore, it is crucial to keep in mind that an amino acid was included in MDIMP, with the idea of making a more tolerable compound on the grounds that adducts of amino acids are highly stable (Flückiger et al., 1984; Mancilla-Percino et al., 2010; Santamaria-Herrera et al., 2016). Indeed, they give rise to less variety of species in solution (e.g., Hofer et al., 2013). Thus, future research may lead to concluding that MDIMP is advantageous for in vivo conditions, possibly based on less adverse effects.

The calcium channels of sperm cells present the same pore motif as that of the $\mathrm{Ca}_{\mathrm{v}} 3.1$ DDDD mutant protein (Navarro et al., 2008). This similitude, combined with the finding that the DDDD mutation decreases the affinity of $\mathrm{Ca}_{\mathrm{v}} 3.1$ for MDIMP, strongly suggests that calcium channels of sperm cells should also exhibit relatively low MDIMP affinity. Likewise, other HVA channels not investigated here (but expressing four glutamates, EEEE) are also expected to be MDIMP-resistant. Cav3.3, on the other hand, is expected to share the same high affinity as $\mathrm{Ca}_{\mathrm{v}} 3.1$ and $\mathrm{Ca}_{\mathrm{v}} 3.2$. Further work is needed to test all these predictions.

In addition to VGCCs, other molecular targets likely mediate the biological activities of MDIMP. For example, it has been shown that the isoindolines derived from $\alpha$-amino acids exert antitumoral effects and also act as enzyme inhibitors (of COX-1, COX-2, and histone deacetylase 8). The corresponding $\mathrm{IC}_{50}$ values for MDIMP were, approximately (in millimolars), 3.2 (cell viability), 0.7 (COX-1), 1.4, (COX-2), and 0.2 (histone deacetylase 8) (Trejo-Muñoz et al., 2013, 2014; Mancilla-Percino et al., 2016). On the other hand, we found that depolarized membrane potentials enhance the affinity of MDIMP for VGCCs. Indeed, at $-50 \mathrm{mV} 130 \mu \mathrm{M}$ of the compound inhibits $\mathrm{Ca}_{\mathrm{V}} 3.1$ by $~ 90 \%$ (instead of the $50 \%$ that is observed at an $\mathrm{HP}$ of $-90 \mathrm{mV}$ ). This indicates the presence of a use-dependent block that could be relevant in electrically active cells. Therefore, we speculate that blood levels as low as $30-40 \mu \mathrm{M}$ (which, in theory, do not compromise cell viability) should be sufficient for reverting an exacerbated excitability in vivo. It is important to emphasize, however, that the therapeutic window of MDIMP has yet to be experimentally determined.

Independently of its potential to be used clinically, MDIMP may also be helpful to dissect the activity of non-T-type calcium channels in native expression systems, specifically in conditions in which HVA channels exhibit characteristics typically associated with LVA channels, for example, in rat atrial myocytes in which the LVA calcium current is thought to reflect the activity of not only $\mathrm{Ca}_{\mathrm{V}} 3.1$ and $\mathrm{Ca}_{\mathrm{V}} 3.2$ but also $\mathrm{Ca}_{\mathrm{V}} 1.3$ and $\mathrm{Ca}_{\mathrm{V}} 2.3$ (Piedras-Rentería et al., 1997; Larsen et al., 2002; Zhang et al., 2005; Ríos-Pérez et al., 2016).

To date, a pharmacological tool that selectively targets $\mathrm{Ca}_{\mathrm{V}} 1.3$ does not exist (Zamponi et al., 2015). A pyrimidine2,4,6-trione derivate $(\mathrm{Cp} 8)$ was thought to represent a selective blocker because it seems to discriminate between $\mathrm{Ca}_{\mathrm{V}} 1.2$ and 
Cav1.3 (Kang et al., 2012). However, this observation was unconfirmed in more recent studies (Huang et al., 2014; Ortner et al., 2014). Moreover, one study found that Cp8 instead stimulates the activity of both channel types (Ortner et al., 2014). Our results suggesting that MDIMP could help to distinguish the activity of L-type $\mathrm{Ca}^{2+}$ channel subtypes in native cells (Fig. 7) are relevant in this context. Nevertheless, we believe that additional efforts are needed to find the most selective compound. MDIMP forms part of an extensive list of molecules termed "amino acid-derived isoindolines" (MancillaPercino et al., 2001), whose biological activities remain practically unexplored. Thus, our ongoing work is focused on characterizing a possible regulation of VGCCs by other members of this family.

In conclusion, we have investigated the mechanisms and specificity of MDIMP effects on VGCCs. Our results indicate that this isoindoline preferentially binds to $\mathrm{Ca}_{\mathrm{V}} 3$ channels, possibly in the selectivity filter, which in turn may elicit a collapse of the pore. In addition, our results suggest that MDIMP is useful to discriminate between $\mathrm{Ca}_{\mathrm{V}} 1.2$ and $\mathrm{Ca}_{\mathrm{V}} 1.3$ (L-type) channels. The corresponding pharmacological relevance for the in vivo condition and the possibility that other amino acid-derived isoindolines also regulate VGCCs have yet to be investigated.

\section{Acknowledgments}

We thank Robert T. Dirksen and Ulises Meza for proving cDNA clones used in this study. We also thank Salvador Carrasco for technical assistance.

\section{Authorship Contributions}

Participated in research design: De La Rosa, Ávila.

Conducted experiments: De La Rosa, García-Castañeda, Ávila.

Contributed new reagents or analytic tools: Nishigaki, Gómora, Mancilla-Percino.

Performed data analysis: De La Rosa, Ávila. Ávila.

Wrote or contributed to the writing of the manuscript: De La Rosa,

Note Added in Proof-The steroisomer nomenclature for the enantiomer of MDIMP was not included in the Fast Forward version published June 25, 2020. The manuscript and supplemental material have now been corrected.

\section{References}

Abderemane-Ali F, Findeisen F, Rossen ND, and Minor DL Jr. (2019) A selectivity filter gate controls voltage-gated calcium channel calcium-dependent inactivation. Neuron 101:1134-1149.e3.

Armstrong CM (1971) Interaction of tetraethylammonium ion derivatives with the potassium channels of giant axons. J Gen Physiol 58:413-437.

Armstrong CM and Cota G (1991) Calcium ion as a cofactor in Na channel gating. Proc Natl Acad Sci USA 88:6528-6531.

Bean BP (1985) Two kinds of calcium channels in canine atrial cells. Differences in kinetics, selectivity, and pharmacology. J Gen Physiol 86:1-30.

Catterall WA (2011) Voltage-gated calcium channels. Cold Spring Harb Perspect Biol 3:a003947.

De La Rosa JAM, García-Castañeda M, Nishigaki T, Gomora JC, Mancilla-Percino T, and Avila G (2019) Pore-blocking effect of isoindoline MDIMP on voltage-gated calcium channels. Biophys J 116:113a-114a.

Díaz D, Bartolo R, Delgadillo DM, Higueldo F, and Gomora JC (2005) Contrasting effects of $\mathrm{Cd} 2+$ and $\mathrm{Co} 2+$ on the blocking/unblocking of human Cav3 channels. J Membr Biol 207:91-105.

Flückiger R, Henson E, Hess GM, and Gallop PM (1984) Mass spectral and HPLC analysis of biological compounds with diphenylborinic acid. Biomed Mass Spectrom 11:611-615.

Garza-López E, Chávez JC, Santana-Calvo C, López-González I, and Nishigaki T (2016) $\mathrm{Cd}(2+)$ sensitivity and permeability of a low voltage-activated $\mathrm{Ca}(2+)$ channel with CatSper-like selectivity filter. Cell Calcium 60:41-50.
Gomora JC, Daud AN, Weiergräber M, and Perez-Reyes E (2001) Block of cloned human T-type calcium channels by succinimide antiepileptic drugs. Mol Pharmacol 60:1121-1132.

Hashimoto N and Kawazu T (2015) Pharmacological rofiles of T-type calcium channel antagonists, in T-type Calcium Channels in Basic and Clinical Science (Schaffer SW and Li M 37-48, Springer, Vienna, Austria.

Hess P, Lansman JB, and Tsien RW (1984) Different modes of Ca channel gating behaviour favoured by dihydropyridine Ca agonists and antagonists. Nature 311: $538-544$.

Hofer A, Kovacs G, Zappatini A, Leuenberger M, Hediger MA, and Lochner M (2013) Design, synthesis and pharmacological characterization of analogs of 2-aminoethyl diphenylborinate (2-APB), a known store-operated calcium channel blocker, for inhibition of TRPV6-mediated calcium transport. Bioorg Med Chem 21:3202-3213. Huang H, Ng CY, Yu D, Zhai J, Lam Y, and Soong TW (2014) Modest CaV1.342selective inhibition by compound 8 is $\beta$-subunit dependent. Nat Commun 5:4481.

Kang S, Cooper G, Dunne SF, Dusel B, Luan C-H, Surmeier DJ, and Silverman RB (2012) CaV1.3-selective L-type calcium channel antagonists as potential new therapeutics for Parkinson's disease. Nat Commun 3:1146.

Larsen JK, Mitchell JW, and Best PM (2002) Quantitative analysis of the expression and distribution of calcium channel alpha 1 subunit mRNA in the atria and ventricles of the rat heart. $J$ Mol Cell Cardiol 34:519-532.

Li J and Sha Y (2008) A convenient synthesis of amino acid methyl esters. Molecules 13:1111-1119.

Lopez-Charcas O, Rivera M, and Gomora JC (2012) Block of human CaV3 channels by the diuretic amiloride. Mol Pharmacol 82:658-667.

Lopin KV, Gray IP, Obejero-Paz CA, Thévenod F, and Jones SW (2012) $\mathrm{Fe}^{2+}$ block and permeation of CaV3.1 $(\alpha 1 \mathrm{G})$ T-type calcium channels: candidate mechanism for non-transferrin-mediated $\mathrm{Fe}^{2+}$ influx. Mol Pharmacol 82:1194-1204.

Mancilla-Percino T, Carrillo L, Zamudio-Rivera LS, Beltrán HI, and Farfán N (2001) Synthesis and characterization of new 2-substituted isoindoline derivatives of $\alpha$-amino acids. Org Prep Proced Int 33:341-349.

Mancilla-Percino T, Correa-Basurto J, Trujillo-Ferrara J, Ramos-Morales FR, Acosta Hernández ME, Cruz-Sánchez JS, and Saavedra-Vélez M (2010) Molecular modeling study of isoindolines as L-type $\mathrm{Ca}(2+)$ channel blockers by docking calculations. J Mol Model 16:1377-1382.

Mancilla-Percino T, Trejo-Muñoz CR, Díaz-Gandarilla JA, Talamás-Rohana P, Guzmán Ramírez JE, Cervantes J, and Figueroa Ortíz A (2016) Isoindoline derivatives of $\alpha$-amino acids as cyclooxygenase 1 and 2 inhibitors. Arch Pharm (Weinheim) 349:175-185.

Navarro B, Kirichok Y, Chung J-J, and Clapham DE (2008) Ion channels that control fertility in mammalian spermatozoa. Int J Dev Biol 52:607-613.

Ortner NJ, Bock G, Vandael DHF, Mauersberger R, Draheim HJ, Gust R, Carbone E, Tuluc P, and Striessnig J (2014) Pyrimidine-2,4,6-triones are a new class of voltage-gated L-type Ca2+ channel activators. Nat Commun 5:3897.

Perez-Reyes E (2003) Molecular physiology of low-voltage-activated t-type calcium channels. Physiol Rev 83:117-161.

Piedras-Rentería ES, Chen CC, and Best PM (1997) Antisense oligonucleotides against rat brain alpha1E DNA and its atrial homologue decrease T-type calcium current in atrial myocytes. Proc Natl Acad Sci USA 94:14936-14941.

Ríos-Pérez EB, García-Castañeda M, Monsalvo-Villegas A, and Avila G (2016) Chronic atrial ionic remodeling by aldosterone: potentiation of L-type $\mathrm{Ca}^{2+}$ channels and its arrhythmogenic significance. Pflugers Arch 468:1823-1835.

Santamaria-Herrera MA, Ríos-Pérez EB, de la Rosa JAM, García-Castañeda M, Osornio-Garduño DS, Ramos-Mondragón R, Mancilla-Percino T, and Avila G (2016) MDIMP, a novel cardiac $\mathrm{Ca}(2+)$ channel blocker with atrial selectivity. Eur J Pharmacol 781:218-228.

Speck K and Magauer T (2013) The chemistry of isoindole natural products. Beilstein J Org Chem 9:2048-2078.

Talavera K, Janssens A, Klugbauer N, Droogmans G, and Nilius B (2003) Pore structure influences gating properties of the T-type Ca2+ channel alpha1G. $J$ Gen Physiol 121:529-540.

Tang L, Gamal El-Din TM, Swanson TM, Pryde DC, Scheuer T, Zheng N, and Catterall WA (2016) Structural basis for inhibition of a voltage-gated $\mathrm{Ca}^{2+}$ channel by $\mathrm{Ca}^{2+}$ antagonist drugs. Nature 537:117-121.

Terlau H and Stühmer W (1998) Structure and function of voltage-gated ion channels. Naturwissenschaften 85:437-444.

Trejo-Muñoz CR, Mancilla-Percino T, Mera-Jiménez E, Correa-Basurto J, and Trujillo-Ferrara JG (2013) Partition coefficient determination of a series of isoindolines-2-substituted and its correlation with their antiproliferative activity on HeLa cells. Med Chem Res 22:4039-4045.

Trejo-Muñoz CR, Mera-Jiménez E, Pinto-Almazán R, Díaz-Gandarilla JA, Correa-Basurto J, Trujillo-Ferrara JG, Guerra-Araiza C, Talamás-Rohana P, and Mancilla-Percino T (2014) Effect of two series of isoindolines over HDAC8 activity and expression. Med Chem Res 23:3227-3234.

Zamponi GW, Striessnig J, Koschak A, and Dolphin AC (2015) The physiology, pathology, and pharmacology of voltage-gated calcium channels and their future therapeutic potential. Pharmacol Rev 67:821-870.

Zhang Z, He Y, Tuteja D, Xu D, Timofeyev V, Zhang Q, Glatter KA, Xu Y, Shin H-S, Low R, et al. (2005) Functional roles of Cav1.3(alpha1D) calcium channels in atria: insights gained from gene-targeted null mutant mice. Circulation 112:1936-1944.

Address correspondence to: Guillermo Ávila, Departamento de Bioquímica Cinvestav-IPN, AP 14-740, México City DF 07000, México. E-mail: gavila@ cinvestav.mx 